\title{
Psychometric Properties of an Agriculture Teacher Efficacy Scale for Senior Secondary Schools in Eswatini
}

\author{
Mpendulo Mathenjwa \\ Lecturer, \\ Department of Agricultural Education and Extension, \\ Faculty of Agriculture, University of Eswatini \\ Marietta P. Dlamini \\ Associate Professor, \\ Department of Agricultural Education and Extension, \\ Faculty of Agriculture, University of Eswatini
}

\begin{abstract}
Teacher efficacy is an important motivational attribute influencing teacher performance and student learning outcomes. Teacher efficacy is multidimensional yet inconsistencies exist on the nature of construct that best measure teacher efficacy across different subjects and contexts. The purpose of the study was to explore the psychometric properties of the agriculture teacher efficacy scale adapted from the Teacher Self-Efficacy Scale (TSES) of Tschannen-Moran and Hoy (2001). Data were collected from 161 beginning agriculture teachers at senior secondary schools in Eswatini. Item analysis and exploratory factor analysis (EFA) using principal component and verimax rotation were used to analyse the data. The findings indicate that the agriculture teacher efficacy scale was reliable (.92) with inter-item correlation value of .41 to .67 and items discrimination index of $\geq .40$ ). EFA revealed that the agriculture teacher efficacy scale had four factors explaining $47.7 \%$ of variance among the items which were instructional strategies, student engagement, classroom management, and practical work management. Conclusion was, the scale is valid to assess agriculture teacher efficacy. Recommendation was, further testing the agriculture teacher efficacy scale across school levels in teaching agriculture.
\end{abstract}

Keywords: psychometric properties; agriculture teacher efficacy scale; factorial analysis

INTRODUCTION

Teacher efficacy (TE) is an important motivational attribute influencing goals teachers set for themselves; how much effort to expend; how they persevere in the face of difficulties; and how they show resilience to failures (Dybowski et al., 2016). TE refers to the teachers' belief in the ability to organise and execute courses of action required to bring about desired outcomes in student learning (Tschannen-Moran et al., 2009). TE is grounded in Bandura's self-efficacy theory, which is a tenet of the Social Cognitive Theory (SCT). Teacher efficacy is domainsensitive and task specific (Bandura, 2006). Bandura (1997) identified four sources of efficacy information, which include: mastery experience; vicarious experiences; verbal persuasion and personal physiological factors. Teacher efficacy is formed by the teacher during pre-service teacher training and continue to develop during teaching practice. Teacher efficacy varies with school level and subject taught.

Tschannen-Moran et al. (1998) proposed an integrated model of teacher efficacy. The integrated model identified mastery experiences, vicarious experiences, verbal persuasion and physiological states as sources of TE. Within the model, the interpretation of the sources of TE 
is the major influence on teacher efficacy beliefs. TE beliefs are established through the social cognitive process, which is social context specific. According to the integrated model, teachers form capability beliefs taking into cognisance the teaching tasks and context. TE beliefs may vary according to three dimensions: strength, level and generality.

Agriculture teacher efficacy can be defined as the teachers' capability belief to bring about the desired learning outcomes among agriculture students. Conceptual clarity surrounding agriculture teacher efficacy is integral to the development of items thought to measure the construct. Zee (2016) cautioned that using omnibus teacher efficacy scales are brought at the expense of the predictive power of teacher efficacy that is domain-specific. Bandura (2006) posited that teacher efficacy scales must be conceptual for optimal domain functioning. Dimensions are viewed as bodies of conceptual knowledge that are organised around concepts or principles that are central to a recognised field of study (Matthews, 1994). Agricultural education is a field of study consisting of three intra-curricular components: 1) classroom instruction, 2) experiential learning through supervised experiences, and 3) leadership activities (Osborne, 2010). A scale purporting to measure agriculture teacher efficacy must be sensitive to these three curriculum components of agriculture at Senior Secondary schools in Eswatini.

The challenge presented by the unique nature of agriculture as a subject revolves around the consideration of the integral pedagogical foundations involved in agriculture teaching at senior secondary schools in Eswatini. An instrument to measure the specific dimensions of agriculture teacher efficacy is not available in Eswatini, except for the universally used Teacher Self-Efficacy Scale (TSES) developed by Tschannen-Moran and Hoy (2001). Questions about the adequacy and robustness of the TSES across national boundaries, subjects, school populations, and teaching environments are beginning to emerge (Klasssen et al., 2009). TSES comprise of three dimensions which include classroom management, instructional strategies and student engagement. Senior secondary school agriculture teacher in Eswatini must inculcate knowledge and understanding, handling of information, practical skills and abilities of learners (Examination Council of Swaziland, 2014). Agriculture teachers demonstrate varying capability beliefs across the various tasks involved in teaching agriculture which include managing student behaviour, engaging students on subject content and managing the practical (school-based supervised agricultural experiences). Thus, an adequate analysis of agriculture teacher efficacy requires a detailed assessment of the teaching task, while allowing respondents to indicate the strength of their efficacy beliefs (Bandura, 1997). Measurements of TSES will be valid if there is a "... continual interplay between theory, research and practice" (Marsh \& Roche 1997). Agriculture teacher efficacy has a huge influence on the practice of teaching agriculture and the associated students learning outcomes, therefore it is imperative to measure agriculture teacher efficacy using valid instruments.

\section{Purpose and research questions of the study}

The study explored the psychometric properties of the Agriculture Teacher Efficacy Scale. The following research questions were used:

1. What items best measure agriculture teacher efficacy?

2. What is the factorial validity of the agriculture teacher efficacy scale?

\section{METHODS}

This study is purely quantitative, descriptive correlational investigating the psychometric properties of an agriculture teacher efficacy scale in Eswatini. 


\section{The Participants}

All beginning agriculture teachers at senior secondary schools during the 2015 calendar year participated in the study. Beginning agriculture teachers were those with five or fewer years of teaching experience. A total of 194 agriculture teachers were eligible but only 161 (83\%) participated in the survey questionnaire. These were teaching agriculture at senior secondary at the time the study was conducted. All the participants, had the Bachelor of Science in Agricultural Education degree, an average teaching experience of 3 years, and 110 (68.3\%) were male whilst $51(31.7 \%)$ were female. The participants had an average age of 28.3 years $(\mathrm{SD}=3.3)$.

\section{Instrument development}

The instrument used in the study was an adapted version of Tschannen-Moran and Woolfolk Hoy's (2001) long-form of TSES. The TSES was adapted following two focus group discussions with experts and practitioners in agriculture teaching. Each focus group had up to ten participants. The participants for the FGD were purposively selected. The participants were practitioners in agriculture who were Agricultural Education degree graduates with seven or more years of teaching experience and experts constituted schools agriculture inspectorate and agriculture curriculum designers. The FGDs adapted TSES to the context, subject matter and varying challenges specific to the teaching of agriculture at senior secondary in Eswatini. Bandura (2006) stated that difficulties associated with the task to be performed must be adequately presented in the items since the scale must differentiate between low and high selfefficacy.

The FGD adapted the semantics of six (6) items of the TSES and added six (6) items specific to the agriculture teaching context. The items were further scrutinized for singular meaning, maximal individual differences, and possibility of socially-desirable responses (Ary et al., 2006; Fowler, 2002; Gall et al., 2007; Hughey, 2010). Additionally, items were reviewed for relevance and similarity to other items within the instrument (DeVellis, 2011) using the grounded theory approach (Strauss and Corbin, 1998; Glaser and Strauss, 1967). All items were rated on a shortened nine-point capability rating scale $(1=$ no capability; $3=$ very little capability; $5=$ little capability; $7=$ moderate capability; and $9=$ a great deal of capability).

The items were further verified for content and face validity by a panel of four Agricultural Education experts at the University of Eswatini. All the four experts were PhD holders in agricultural education. The experts judged the items for clarity of wording and appropriateness of each item for use with the targeted participants, comprehensiveness, and relevance to senior secondary agriculture teaching. Feedback from the experts were used for refinement of the items. The adapted TSES had a total of 30 items, of which 8 items sought to measure capability beliefs in classroom management; 13 items on instructional strategies efficacy and 9 items assessing student engagement efficacy. The modified TSES was found to be reliable (Cronbach alpha $=0.92$ ) when pilot- tested on experienced agriculture teachers with seven (7) or more years of teaching experience.

\section{Data Collection}

The Director of Education in the Ministry of Education and Training (MoET) granted ethical clearance and approval to use senior secondary agriculture teachers as respondents for the study. Participation of the teachers was voluntary and with informed consent. Also, data were analysed at macro-level to ensure personal information confidentiality. This means that data collection process took place in each school during scheduled meetings. The agriculture TSES was administered to all beginning agriculture teachers at senior secondary school. Data were collected for three months (14 $4^{\text {th }}$ September to $15^{\text {th }}$ November) during the 2016 calendar year. 
The number of cases were enough following Hatcher (1994) and Gorsuch (1983) recommendations that the number of subjects should be five times larger than the number of variables in the instrument.

\section{Data Analysis}

The data were first subjected to preliminary data analysis based on item descriptives including means, standard deviations, skewness, inter-item correlation and Cronbach's alpha if item deleted. The goal of descriptive statistics and item analysis was to remove irrelevant items from the scale measuring agriculture teacher efficacy. Choi and Jang (2014) stated that exploratory factor analysis (EFA) can be used for assessment of variables prior to statistical test of hypothesis. EFA is a statistical method that increases the reliability of the scale by identifying inappropriate items that can be removed in an instrument or scale. Moreover, EFA provides construct validity evidence of self-reporting scales (Thompson, 2004). Hence, the study employed EFA to assess the items that generate the factors (latent variables) for an agriculture teacher efficacy scale. Orthogonal verimax rotation was used to classify items in their respective factors. Using the objectives of the study, the following statistical procedures were followed: The quality of items were assessed by conducting item analysis in terms of item descriptives, inter- item correlation, item discrimination, and alpha-if-item-deleted indices. The factorial structure of the scale were examined by the principal components analysis (PCA) based on factor loadings, Kaiser rule and scree plot inspection.

\section{RESULTS AND DISCUSSION}

The results of item analysis are presented in Table 1 . The item means of agriculture teacher efficacy ranged from 5.32 to 7.45 with an average standard deviation of 1.09, though one item (Item 18) had a fairly large standard deviation of 4.24 and with positive and high skewness. Data on item 18 were asymmetric and did not meet the normality prerequisite for EFA. This indicated that beginning agriculture teachers varied greatly concerning their capability to integrate content on current advances in agriculture. 
Table 1. Item Analysis of Agriculture Teacher Efficacy Scale

\begin{tabular}{llllccl}
\hline Item & $\mathbf{M}$ & SD & $\begin{array}{c}\text { Skew } \\
\text { ness }\end{array}$ & $\begin{array}{c}\text { Inter-item } \\
\text { correlation }\end{array}$ & $\begin{array}{c}\text { Cronbach's } \\
\text { Alpha if Item } \\
\text { Deleted }\end{array}$ & Decision \\
\hline 1 & & & & & .92 & Retain \\
2 & 7.01 & 1.64 & -.98 & .59 & .92 & Retain \\
3 & 6.91 & 1.66 & -.58 & .59 & .92 & Retain \\
4 & 6.64 & 1.86 & -.54 & .46 & .92 & Retain \\
5 & 7.34 & 1.62 & -.89 & .46 & .96 & Retain \\
6 & 5.86 & 1.84 & -.37 & .46 & .92 & Retain \\
7 & 7.03 & 1.72 & -.87 & .52 & .92 & Retain \\
8 & 6.37 & 1.75 & -.74 & .53 & .92 & Retain \\
9 & 7.26 & 1.57 & -.29 & .50 & .92 & Retain \\
10 & 7.45 & 1.60 & -.71 & .60 & .92 & Retain \\
11 & 6.58 & 1.79 & -.95 & .55 & .92 & Retain \\
12 & 6.57 & 1.79 & -.46 & .54 & .92 & Retain \\
13 & 6.57 & 1.84 & -.38 & .55 & .92 & Retain \\
14 & 6.65 & 1.85 & -.60 & .60 & .92 & Retain \\
15 & 6.90 & 1.81 & -.56 & .57 & .92 & Retain \\
16 & 6.42 & 2.02 & -.45 & .66 & .92 & Retain \\
17 & 6.05 & 1.88 & -.46 & .64 & .92 & Retain \\
18 & 7.41 & 1.72 & -1.20 & .46 & .92 & Remove \\
19 & 6.76 & 4.24 & 9.25 & .16 & .93 & Retain \\
20 & 6.35 & 1.84 & -.43 & .60 & .92 & Retain \\
21 & 6.72 & 2.01 & -.54 & .41 & .92 & Retain \\
22 & 6.96 & 1.85 & -.53 & .49 & .92 & Retain \\
23 & 6.91 & 2.11 & -.91 & .52 & .92 & Retain \\
24 & 6.58 & 1.98 & -.66 & .43 & .92 & Retain \\
25 & 5.32 & 2.29 & -.25 & .47 & .92 & Retain \\
26 & 6.38 & 1.94 & -.51 & .58 & .92 & Retain \\
27 & 5.88 & 1.97 & -.63 & .51 & .92 & Retain \\
28 & 6.55 & 2.27 & -.64 & .57 & .92 & Retain \\
29 & 6.61 & 1.99 & -.82 & .66 & .92 & Retain \\
30 & 7.01 & 1.85 & -.88 & .67 & .92 & Retain \\
\hline & 7.42 & 1.80 & -1.22 & .63 & .92 & \\
\hline
\end{tabular}

The agriculture teacher efficacy scale had an inter-item correlation value of .41, indicating a high degree of good internal consistency (Brckalorenz et al., 2013). For the homogeneity test, the item-total correlation coefficients ranged from .16 to .67. Reasonable values for item discrimination should be greater than .40 (Alkharusi et al., 2017). Items with values outside these ranges should be considered for removal from the scale. One item with the item-total correlation coefficient of .16 was removed from the 30 items at this stage on the basis of the item analysis results. The item removed involved integrating current advances in agriculture. The Cronbach's alpha if-item deleted indicates the Cronbach's alpha score after removing an item, the agriculture TSES reliability score was .92. For all items of the instrument, the score went down if an item was deleted except for if item18 - involving integrating current advances in agriculture, which was ultimately removed prior to exploratory factor analysis.

Morgado et al. (2017) posited that items generated using both inductive and deductive approaches provide contextual and genuine information about the construct. The decision to use .40 as a threshold minimum for inter-item correlation ensured parsimony of the agriculture teacher efficacy scale. The inter-item correlation minimum of .40 used in the study is above the minimum level of .30 advocated by Kline (1979). Twenty-nine (29) items of the 30 items initially generated were retained for factor principal component analysis. The retained items were parsimonious and conceptually robust for agriculture teacher efficacy scale. 
Henson and Roberts (2006) opined that factor retention in exploratory analysis must be based on a multiple criteria and reasoned reflection. A four decision rule was used to decide on the number of factors to retain for the agriculture teacher efficacy scale after the verimax rotations. First, as a rule of thumb, only variables with loadings of 0.40 and above were interpreted (Tabachnick \& Fidell, 2007). Secondly, the Kaiser's K1 rule was used whereby items with Eigen value of $\geq 1$ were to be selected. Eigen value assesses the contribution of the factor to the model built by factor analysis, with a value less than 1 suggesting low contribution of the factor in explaining the variance of the original variables (Kaiser, 1974). Thirdly, the scree plot was inspected and indicated a significant elbow after four factors (Figure 1). The first four factors were considered appropriate for retention. The cut-off point criterion of .40 for factor loading (Stevens, 2002) was used, thus irrelevant items that did not fit well in designated factors were disqualified. Only items with an internal consistency of .40 and above constituted factors of the agriculture teacher efficacy scale. Lastly, a threshold of four items per factor were used.

Figure 1: Scree plot

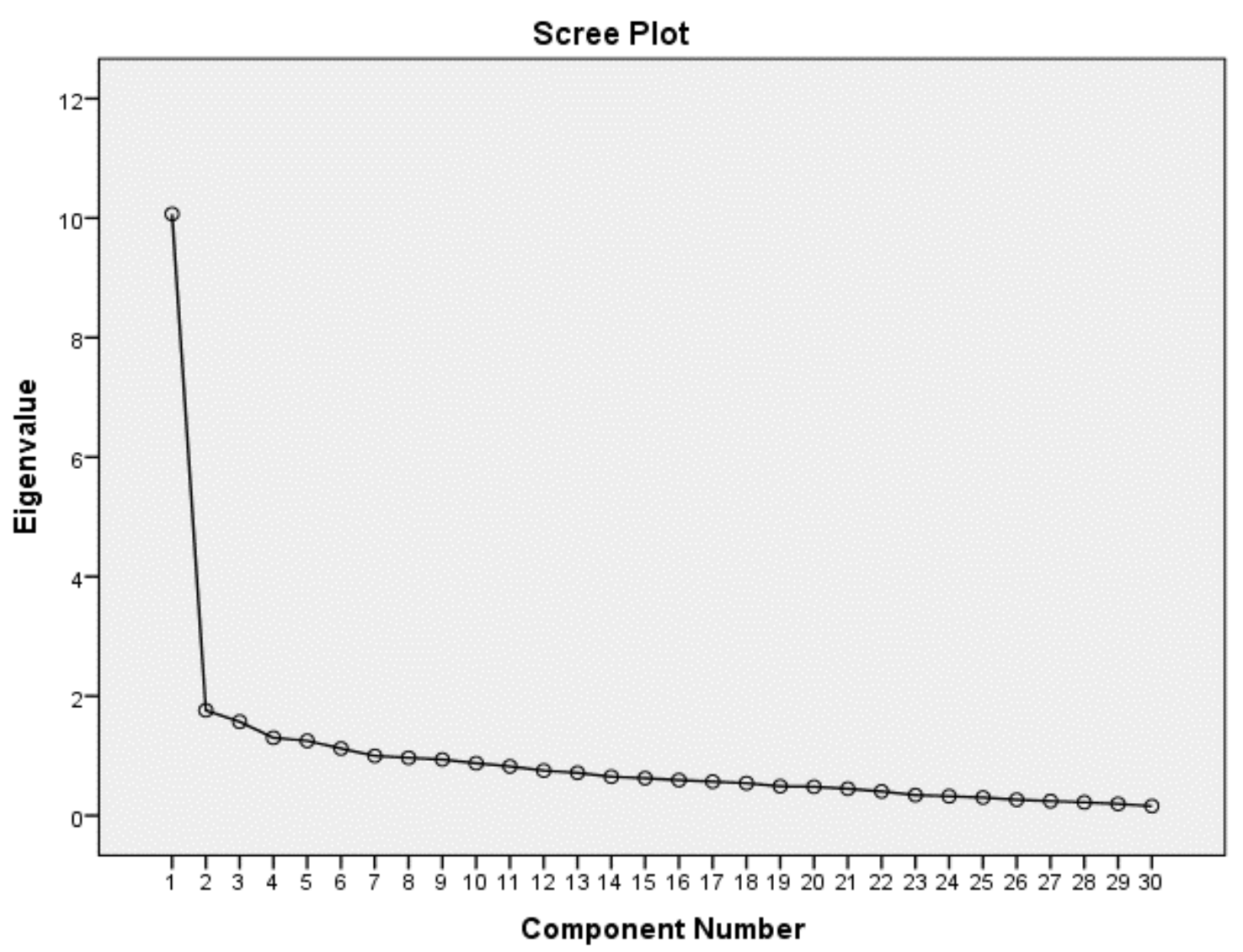

Compliance of data with EFA were ensured by screening for normality, linearity, multicollinearity, and singularity. Furthermore, the data were tested for factorability by the use of Kaiser-Meyer-Olkin (KMO) and Barlett Test of Sphericity. Using SPSS 20.0, an EFA was conducted with principal axis factoring using varimax rotation on the remaining 29 items to identify the underlying structure of Agriculture Teacher Efficacy scale. Results of analysis of the scree plot, Eigen values, item factor loadings, and overall factor interpretability were used to determine the factor solution (Worthington \& Whittaker, 2006). The Kaiser-Meyer-Olkin index was .89, which indicates that the sample was appropriate for factor analysis (Pett, Lackey \& Sullivan, 2003). The Bartlett's test of sphericity was, $\mathrm{X}^{2}(435)=2087.14, \mathrm{p}<.001$ indicating significant correlations for the 29 items of the agriculture teacher efficacy. 
Table 2 presents the exploratory factor analysis results of the agriculture teacher efficacy scale. The PCA revealed six factors with Eigen values exceeding 1, which explained a total of 57\% of the variance. Only four factors which accounted $47.7 \%$ variance in agriculture teacher efficacy were retained following the four-decision rule. The four factors constituted 27 items which loaded $\geq .41$ on the primary factor (name here) and items 24 and 25 were deleted. The two items were deleted since they loaded on individual factors yet factor retention decision was based on a four-item threshold (Osborne \& Costello, 2009; Field, 2009). The four factors were retained, since they were interpretable using the social cognitive and self-efficacy theories pertaining to teaching in the school settings.

The first factor explained $15.7 \%$ variance, consisted of 10 items with factor loadings range of $.41 \leq .71$ and was labelled as instructional strategies (IS) efficacy. The internal consistency test showed a Cronbach alpha value of .87 for the IS efficacy factor. Items that loaded to IS dealt with ability of teachers to respond to questions posed by students and providing appropriate instructional challenges to students. The second factor accounted for $11.5 \%$ variance made up of 6 items with factor loading of .43 $\leq .76$ and described as student engagement (SE) efficacy. The reliability coefficient was .82 for student engagement factor.

The third factor explained $11.3 \%$ variance, consisted of seven items with factor loadings ranging from .43 to .76. This factor was labelled as classroom management (CM) efficacy and showed a Cronbach Alpha value 0.79. The fourth factor accounted for $9.2 \%$ variance and constituted four items with factor loadings between .63 and .66. According to the nature of the items constituting the fourth factor and in light of the nature of agriculture as a subject, the factor was named practical work management (PWM) efficacy and had a reliability score of 0.77. The naming of the factor was based on Matsunanga (2010) guidelines which include that factor names should be kept short, theoretically meaningful and descriptive of the relationships they hold to the manifest variates. 
Table 2. Exploratory Factor Analysis Results of the Agriculture Teacher Efficacy Scale $(\mathrm{n}=161)$

\begin{tabular}{|c|c|c|c|c|}
\hline \multirow[b]{2}{*}{ Agriculture teacher efficacy scale } & \multicolumn{4}{|c|}{ FACTOR } \\
\hline & 1 & 2 & 3 & 4 \\
\hline 1. Get my learners to adhere to classroom rules & & & .53 & \\
\hline 2. Control disruptive behaviour in my classroom & & & .70 & \\
\hline 3. Establish routines to keep activities running smoothly & & & .69 & \\
\hline 4. Get my learners to observe safety rules during subject practicals & & & .57 & \\
\hline 5. Get through to most difficult learners in class & & & .76 & \\
\hline 8. Respond well to defiant students & & & .54 & \\
\hline 11. Gauge learners comprehension of what I have taught & & & .43 & \\
\hline 9. Develop questions that are appropriate for my learners & .50 & & & \\
\hline $\begin{array}{l}\text { 10. Provide alternative explanations when my learners are } \\
\text { confused }\end{array}$ & .54 & & & \\
\hline 12. Use a variety of assessment strategies & .65 & & & \\
\hline 13. Simplify curriculum for my learners & .74 & & & \\
\hline 14. Use different teaching methods in my classes & .62 & & & \\
\hline 15. Teach learners to think critically & .65 & & & \\
\hline 16. Teach my learners at all levels of cognition & .61 & & & \\
\hline 17. Respond to difficult questions from learners & .47 & & & \\
\hline 19. Provide appropriate challenges for capable learners & .65 & & & \\
\hline 21. Assess the practical work by adhering to the syllabus criterion & .41 & & & \\
\hline 6. Manage all activities related to crop production & & & & .63 \\
\hline 7. Supervise the learners in animal production & & & & .64 \\
\hline 22.Supervise investigatory projects for learners & & & & .66 \\
\hline 23.Manage the tools for the department & & & & .62 \\
\hline 20. Link curriculum instruction with learners' home practices & & .44 & & \\
\hline 26. Make timely entries to the learners' academic portfolios & & .47 & & \\
\hline 27. Finishing the syllabus within the set deadline & & .56 & & \\
\hline 28. Get my learners to actively participate in class & & .62 & & \\
\hline 29. Motivate learners to show interest in their school work & & .76 & & \\
\hline 30.Help students value learning agriculture & & .73 & & \\
\hline Variance (\%) explained & 15.7 & 11.5 & 11.3 & 9.2 \\
\hline Internal reliability $(\alpha)$ & .87 & .82 & .79 & .77 \\
\hline Total variance explained & 47. & & & \\
\hline
\end{tabular}

The four-factor structure of the instrument indicate that agriculture teacher efficacy is multidimensional. The first three factors (IS, CM \& SE) of the scale are consistent with inservice teacher efficacy factor structure (Klaasen et al., 2009; Tsigilis et al., 2010; Duffin et al., 2012). The fourth factor (PWM) is unique to teaching agriculture as a subject at senior secondary school, which involves learning by doing and experiential learning. The findings did not confirm the two factor structure of TES of Gibson and Dembo (1984) which included personal teaching efficacy and general teaching efficacy. Bandura (2006) affirmed that teacher efficacy instruments must be context-specific and task-specific to improve validity.

\section{CONCLUSION}

Agriculture teacher efficacy is multidimensional, constituting of four factors which include efficacy in classroom management, instructional strategies, student engagement and practical work management. The four factors of the agriculture teacher efficacy scale correspond to the dimensions functioning of agriculture teaching at senior secondary in Eswatini. The agriculture teacher efficacy scale is valid to assess agriculture teacher efficacy at senior secondary school in Eswatini. To further verify the stability of the agriculture teacher efficacy scale, future researchers can study the factorial structure of the scale across different school levels (primary, secondary and senior secondary) and pre-service teacher training. Finally, additional studies are needed to assess the predictive validity of the scale in terms of teacher effectiveness in teaching agriculture and subsequent students' academic performance. The 
results obtained through this study will prove to be an example to the adaptation of the teacher efficacy scale to different subjects and teaching environments.

\section{ACKNOWLEDGEMENTS}

The researchers would like to thank all the participant agriculture teachers for their invaluable contributions.

\section{LITERATURE CITED}

Alkharusi, H., Aldhafri, S., Al-Hosni, K., Al-Busaidi, S., Al-Kharusi, B., Ambusaidi, A., \& Alrajhi, M. (2017). Development and Validation of a Scale for Measuring Mathematics Teaching Self-Efficacy for Teachers in the Sultanate of Oman. International Journal of Instruction, 10(3), 143 - 58. https://doi.org/10.12973/iji.2017.10310a

Ary, D., Jacobs, L. C., Razavieh, A., \& Sorensen, C. 2006. Introduction to research in education ( $7^{\text {th }}$ ed.). California: Thomson Wadsworth

Bandura, A. (2006). Guide for constructing self-efficacy scales. In F. Pajares \& T. Urdan (Eds.), Adolescence and education: Self-efficacy and adolescence 5. Greenwich, CT: Information Age.

Bandura, A. (1997). Self-efficacy: The exercise of control. New York: Freeman.

Bartlett, M. S. (1954). A note on the multiplying factors for various $\mathrm{x}^{2}$ approximations. Journal of the Royal Statistical Society, Series B, 16, 269-298

Brckalorenz, A., Chiang, Y., \&. Nelson Laird, T. (2013). Internal consistency. FSSE Psychometric portfolio. Retrieved from fsse. Indiana. Edu. 27 may 2018.

Choi, S., \& Jang, S. Y. (2014). A Review of exploratory factor analysis (EFA): Practices in english education research in Korea. Advanced Science and Technology Letters, 47(Education), 244-248.

http://doi.org/http://dx.doi.org/10.14257/astl.2014.47.56

DeVellis, R. F. (2011). Scale development: Theory and applications. Newbury Park: Sage Publications.

Duffin, L. C., French, B. F., \& Patrick, H. (2012). The Teachers' Sense of Efficacy Scale:Confirming the factor structure with beginning pre-service teachers. Teaching and Teacher Education, 28(6), 827-834.

Dybowski, C., Kriston, L., \& Harendza, S. (2016). Psychometric properties of the newly developed Physician Teaching Self-Efficacy Questionnaire (PTSQ)

Examination Council of Swaziland. (2014). SGCSE Agriculture Syllabus 6882

Field, A. (2009). Discovering Statistics using SPSS. Sage: London.

Fowler, F. J. J. (2002). Survey Research Methods. New York: Sage Publication Inc.

Gall, M. D., Gall, J., \& Borg, W.R. (2007). Educational Research: An Introduction. Boston: Allyn \& Bacon.

Gibson, S. \& Dembo, M. H. (1984). Teacher efficacy: a construct validation, Journal of Educational Psychology, 76(4), 569-582

Glaser, B., \& Strauss A. (1967). The Discovery of Grounded Theory: Strategies for Qualitative Research. Mill Valley, CA: Sociology Press.

Gorusch, R. L. (1983). Factor analysis $2^{\text {nd }}$ Ed. Hillside, NJ: Lawrence Erlbaum Associates

Hatcher, L. (1994). A step by step approach to using SAS systems for factor analysis and structural equation modelling. Cary, N.C; SAS Institute, Inc.

Henson, R. K. \& Roberts, J. K. (2006). Use of Exploratory Factor Analysis in Published Research Common Errors and Some Comment on Improved Practice. Educational and Psychological Measurement, 66 (3), 393-416.

Hughey, S. L. (2010). Development of a teaching writing self-efficacy scale. PhD Diss. submitted in the in the Graduate School of the University of Alabama Tuscaloosa, Alabama.

Kaiser, H. F. (1974). An index of factorial simplicity. Psychometrika, 39, 31-36.

Klassen, R. M., Bong, M., Usher, E. L., Chong, W. H., Hua, V. S., Wong, I. Y. F., \& Georgiou, T. 2009. Exploring the validity of a teachers' self-efficacy scale in five countries. Contemporary Educational Psychology, 34, 67-76. doi:10.1016/j.cedpsych.2008.08.001 
Kline, P. (1979). Psychometrics and psychology. Academic Press, London.

Lent, R. W., Hill, C. E., \& Hoffman, M. A. (2003). Development and validation of the counsellor activity self-efficacy scales. Journal of Counselling Psychology, 50(1), 97-108.

Marsh, H. W. \& Roche, L. A. (1997). Making students' evaluations of teaching effectiveness effective: The critical issues of validity, bias, and utility. American Psychologist, 52: 1187-1197.

Matsunanga, M. (2010). How to factor analyse your data right. Do's, Don'ts and How-to's. International Journal of Psychological research, 3 (1), 97-110.

Matthews, M. R. (1994). Science teaching: The role of history and philosophy of science. New York, NY: Routledge.

Morgado, F. F. R., Meireles, J. F. F., Neves, C. M., Amaral, A. C. S., \& Ferreira, M. E. C. (2017). Scale development: ten main limitations and recommendations to improve future research practices. Reflexão e Crítica 30 (3), 1 - 20. DOI 10.1186/s41155-016-0057-1

Noddings, N. (1988). Philosophy of education. Boulder, CO: Westview Press.

Osborne, E. (2010). Taking agricultural education to the next level. Journal of Agricultural Education 52 (1), 1-8. DOI: $10.5032 /$ jae.2011.01001

Osborne, J. W. \& Costello, A. B. (2009). Best practices in exploratory factor analysis: Four recommendations for getting the most from your analysis. Pan-Pacific Management Review, 12(2), 131-146.

Pett, M. A., Lackey, N. R. \& Sullivan, J. J. (2003). Making sense of factor analysis: The use of factor analysis for instrument development in health care research. Thousand Oaks, CA: Sage.

Raubenheimer, J. (2004). An item selection procedure to maximize scale reliability and validity. SA Journal of Industrial Psychology, 30, 59-64.

Sheu, H. B. \& Lent, R. W. (2007). Development and initial validation of the multicultural counseling self-efficacy scale. Psychotherapy: Theory, Research, Practice, Training, 44, 30-45.

Stevens, J. P. (2002). Applied multivariate statistics for social sciences (4th Edition). Hilsdale, NJ: Erlbaum.

Strauss, A.L., \& Corbin, J. (1998). Basics of qualitative research: Grounded theory procedure and techniques. Newbury Park, CA: Sage Publication Inc.

Tabachnick, B. G. \& Fidell, L. S. (2007). Using multivariate statistics, $5^{\text {th }}$ ed. Boston, MA: Allyn and Bacon.

Thompson, B. (2004). Exploratory and confirmatory factor analysis: understanding concepts and applications. American Psychological Association, Washington DC.

Tschannen-Moran, M. \& McMaster, P. (2009). Sources of self-efficacy: Four professional development formats and their relationship to self-efficacy and implementation of a new teaching strategy. The Elementary School Journal, 110 (2), 228-45.

Tschannen-Moran, M., Woolfolk Hoy, A. \& Hoy, W. K. (1998). Teacher-efficacy: Its meaning and measure. Review of Educational Research, 68 (2), 202-248.

Tschannen-Moran, M. \& Woolfolk Hoy, A. (2001). Teacher efficacy: Capturing an elusive construct. Teaching and Teacher Education, 17 (7), 783-805.

Tsigilis, N., Koustelios, A. \& Grammatikopoulos, V. (2010). Psychometric properties of the teachers' sense of efficacy scale within the Greek educational context. Journal of Psychoeducational Assessment, 28 (2), $153-162$. doi: $10.1177 / 0734282909342532$

Worthington, R. L. \& Whittaker, T. A. (2006). Scale development research: A content analysis and recommendations for best practices. The Counselling Psychologist, 34, 806-838.

Zee, M. (2016). From general to student-specific teacher self-efficacy. PhD Diss. submitted in the University of Amsterdam, Holland 